\title{
Artículos
}

\section{Los acuerdos de París sobre el cambio climático: ¿Un camino para salvar el planeta?}

\author{
René Mendoza Vidaurre*
}

Recibido: febrero de 2016 / Aceptado: marzo de 2016

Cuando las olas del mar golpean nuestro pecho, al mismo tiempo sentimos que una corriente de agua jala nuestros pies en dirección contraria. En medio de presiones de todos lados, el 12 de diciembre del 2015, representantes de 195 países reunidos en París lograron el primer acuerdo universal y vinculante para salvar el planeta. En este artículo argumentamos que los Acuerdos de París son como las "olas" que nos permiten surfear, pero precisamos discernir "la corriente de agua debajo de las olas", la resaca que nos puede ahogar. Para ello, iniciamos con un breve marco teórico, luego identificamos el problema del cambio climático, lo ponemos en perspectiva histórica, listamos los acuerdos alcanzados en París y sus efectos en el largo plazo, discernimos "la corriente debajo de las olas" del acuerdo, dimensionamos los desafíos y, posicionándonos desde las organizaciones campesinas, indígenas y afrodescendientes, sugerimos mecanismos concretos de mitigación del cambio climático.

Palabras clave: Cambio climático/ Acuerdos de París / nuevas perspectivas

Toma una piedra en tu mano y cierra tu puño alrededor hasta que empiece a latir, vivir, hablar y moverse.

Poema Sámi

PhD en estudios del desarrollo, colaborador de Wind of Peace Foundation (WPF) (http:// peacewinds.org/research/), investigador asociado de IOB-Universidad de Amberes (Bélgica). Correo electrónico: rmvidaurre@gmail.com 


\section{El dilema del bien común del clima}

Hay una estrecha relación entre bienes comunes (colectivos o públicos) y el cambio climático; la atmósfera es un bien de todos y a la vez es limitado, que puede ser explotado y que realmente ha sido explotado en exceso (contaminación). La cuestión es: si sabemos que el clima nos beneficia a todos, ¿por qué la atmósfera es contaminada? Hardin (1968), en un contexto de guerra fría marcado por la dicotomía estado-mercado, argumentó que los individuos racionales, maximizando sus ventajas privadas y socializando sus costos, acaban con los recursos comunes, por lo que éstos están condenados a ser acabados (privatizados) -de ahí la palabra tragedy. El dilema es que todos queremos una atmósfera no contaminada, pero nuestras acciones racionales individuales provocan un resultado irracional colectivo, el cambio climático.

Olson (1965) identifica la causa de ese dilema en el free rider, el oportunista que considera que recibirá beneficios independientemente de su contribución, lo que resulta en un supuesto generalizado. Olson sugiere trabajar en pequeños grupos y proveer mecanismos de sanción/incentivos, para que los comunes se salven. Ostrom (1990) critica a Hardin por el carácter determinista de su teoría ("tragedia") bloqueando el progreso humano y, sobre la base de casos de gestión comunal, encuentra que los comunes no desaparecen, que pueden ser bien gestionados en caso hay claridad de las reglas (leyes), los métodos colectivos y decisiones son tomados colectivamente, hay mecanismos locales y públicos de resolución de conflictos incluyendo sanciones a quienes violentan las reglas, y en caso de que la autodeterminación de las comunidades sea reconocida por las autoridades de más alto nivel. Y ahí no hay "tragedy"; las culturas entienden que los comunes son ambientes que hacen posible un comportamiento sostenible y racional (De Biase, 2014).

Resolver ese dilema de la acción colectiva requiere de conocimiento, particularmente en el caso que nos concierne. Aquí, sin embargo, emerge otro dilema: la ciencia genera información que nos provoca incertidumbre a la vez que dependemos de esa información. Siguiendo a Beck (1986), vivimos en una sociedad de riesgo ("sociedad moderna"), no solo de clases ("sociedad tradicional"). Nuestro medio es un ambiente donde el conocimiento, como el ser, determina la conciencia, cuya formación es diferente a la conciencia de antes porque los peligros no vienen de ricos y pobres sino que ambos tienen el mismo problema en esta sociedad de riesgo, aunque con resultados diferenciados -como un terremoto del mismo grado tiene efectos diferentes en Haití que en los Estados Unidos. La ciencia informa sobre el aumento de temperatura y sugiere su control, incluso algunos expresan su fe en que el avance de la tecnología resolverá el cambio climático. Pero la ciencia no puede predecir las consecuencias de ese aumento por el grado de complejidad del mismo. La paradoja es que hay incertidumbre sobre el conocimiento a la vez que se depende de él (Beck, 1986).

Ambos dilemas, de la acción colectiva y del conocimiento, se mueven bajo condiciones estructurales, las cuales son ideas, intereses y patrones de organización e institucionalidad fundadas durante siglos, que son muy excluyentes y generalmente dominadas por pequeñas elites. En este marco formulamos varias tesis: hay estructuras 
Encuentro №. 103, 6-27, 2016

que subyacen la contaminación de la atmósfera y la primacía de la racionalidad individual, lo que ha tenido efectos perversos; los comunes (la atmósfera), siguiendo a Ostrom, no son "tragedy", pero conflictos que deben ser analizados como puntos de partida desde una perspectiva de política económica; el dilema de acción colectiva y la incertidumbre pueden ser resueltos a través de un conocimiento producido por "comunidades epistémicas" que incluyan a los "científicos civiles" (familias vulnerables y sus organizaciones) y a los "científicos naturales y sociales".

\section{Calentamiento global}

¿De qué se trata? La energía solar atraviesa la atmósfera, parte de esa energía es absorbida por la superficie y otra parte es reflejada (rebota); una parte de esa radiación reflejada es retenida por los gases de efecto invernadero (GEI) y otra parte vuelve al espacio. Es decir, los GEI están en la atmósfera, retienen parte del calor del sol y al estar dentro de un rango determinado, mantienen una temperatura adecuada

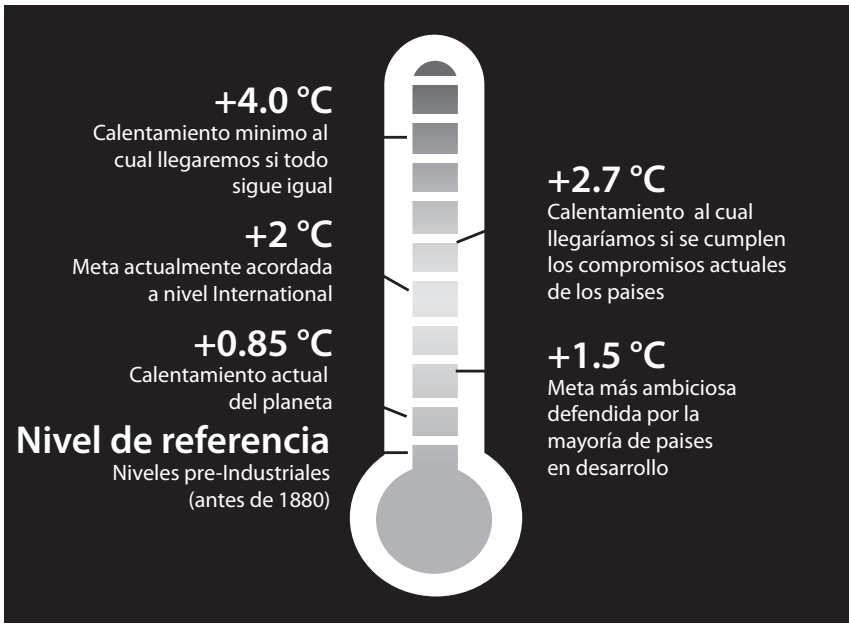

Ilustración1. Incremento de temperatura al 2100 Fuente: Conferencia de Partes (COP) basado en la Convención Marco de las Naciones Unidas sobre el Cambio Climático (CMNUCC). http://myalbum.com/ album/boFLr8B9S4j0 para la vida.

El problema es cuando esos GEI aumentan en la atmósfera, con ello retienen más calor y hacen que la temperatura de la tierra aumente. Si tomamos la temperatura promedio mundial del período preindustrial como referencia (ver Ilustración 1), la temperatura para el 2012 subió 0.85 grado Celcius (conocido como centígrado, símbolo 0 ) con relación al período preindustrial. Si este aumento sigue sin cambio alguno, la temperatura para el 2100 subirá 4.0 0C, situación en la que se cree el planeta sobrevivirá pero no la raza humana. Los países G-7 han prometido cero emisión de carbono para el mismo año 2100, pero nos podríamos preguntar si están seguros de ello, porque para esa fecha no habrían seres humanos capaces de emitirlo. En los acuerdos de París alcanzados en diciembre de 2015, las partes (países) plantearon nuevos compromisos para quedarse debajo del aumento de 20C en comparación al nivel pre-industrial. Sin embargo, aun cuando dichos acuerdos se cumplan, el gasto del presupuesto de carbono no solo llegaría al 107.3\% en 2080 (ver Ilustración 2), sino que podrían alcanzarse 2.70C, reconocido en los 
mismos Acuerdos: "Observa con preocupación que los niveles estimados de las emisiones agregadas de gases de efecto invernadero en 2025 y 2030 resultantes de las contribuciones previstas determinadas a nivel nacional no son compatibles con los escenarios de $2^{\circ} \mathrm{C}$ de menor costo sino que conducen a un nivel proyectado de 55 gigatoneladas en 2030, y observa también que, para mantener el aumento de la temperatura media mundial por debajo de $2^{\circ} \mathrm{C}$ con respecto a los niveles preindustriales, mediante una reducción de las emisiones a 40 gigatoneladas..." (cap 2, art. 17).

Hablamos de un presupuesto de carbono (carbon Budget), porque se ha fijado una cantidad de carbono a emitirse para no pasar $\operatorname{los} 2^{\circ} \mathrm{C}$ de calentamiento global (promedio) con relación al período pre industrial. La Ilustración 2 muestra cómo hemos ido gastando ese presupuesto de carbono, evidenciando el peligro de la "resaca". Entre 1860 y 1965 se gastó (emitió) la cuarta parte de ese presupuesto (24.4\%), gasto que para el año 2000 ya era la mitad de ese presupuesto (53\%), y para 2012 se gastó casi tres cuartas partes del presupuesto (67.1\%). Esto es lo que la Ilustración 1 muestra como $0.85^{\circ} \mathrm{C}$ de calentamiento global. Luego, la Ilustración 3 nos da otro dato, que en noviembre de 2015 el calentamiento global superó el "techo" de $1^{\circ} \mathrm{C}$ por encima de los niveles preindustriales.

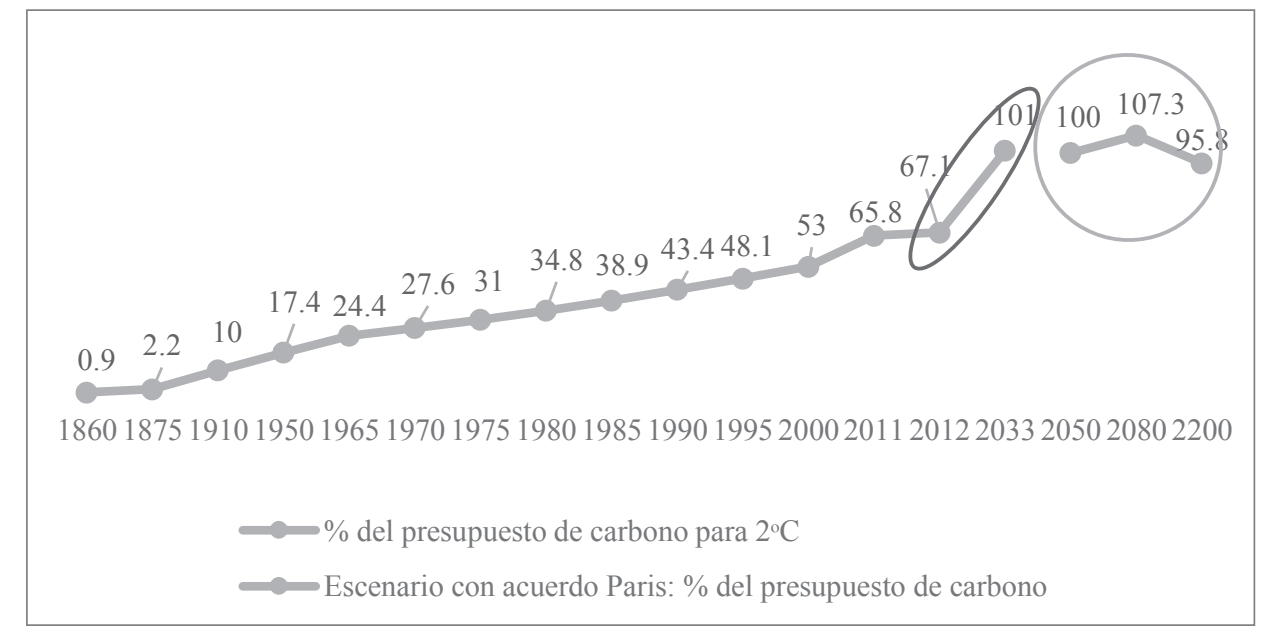

Ilustración $2 . \%$ del $2{ }^{\circ} \mathrm{C}$ usado debido al aumento de las emisiones acumuladas de $\mathrm{CO}_{2}$

Fuente: basado en World Resources Institute

Además, el gasto del presupuesto de carbono es cada vez más rápido. En consecuencia, el aumento del calentamiento global también se da de forma más rápida. El problema, según IPCC (International Panel on Climate Change, Estocolmo 26-8-2013) $)^{1}$ es que cuando la temperatura pase $1.6+$ y $2.0+$, esa temperatura permanecerá por cientos de años no importando lo que hagamos. Ese umbral, al ritmo que llevamos, lo cruzaremos en pocos años. Para 2033 habremos 
gastado el $100 \%$ del presupuesto de carbono y el calentamiento global subirá $2^{\circ} \mathrm{C}$, y para el año 2100 habrá subido $4^{\circ} \mathrm{C}$. Recordemos que estos datos son un promedio mundial, lo que significa que el aumento de temperatura de $2^{\circ} \mathrm{C}$ con relación a los niveles preindustriales, en regiones tropicales podría ser de $3^{\circ} \mathrm{C}$ o más, lo que será catastrófico para la vida -la tierra y la humanidad.

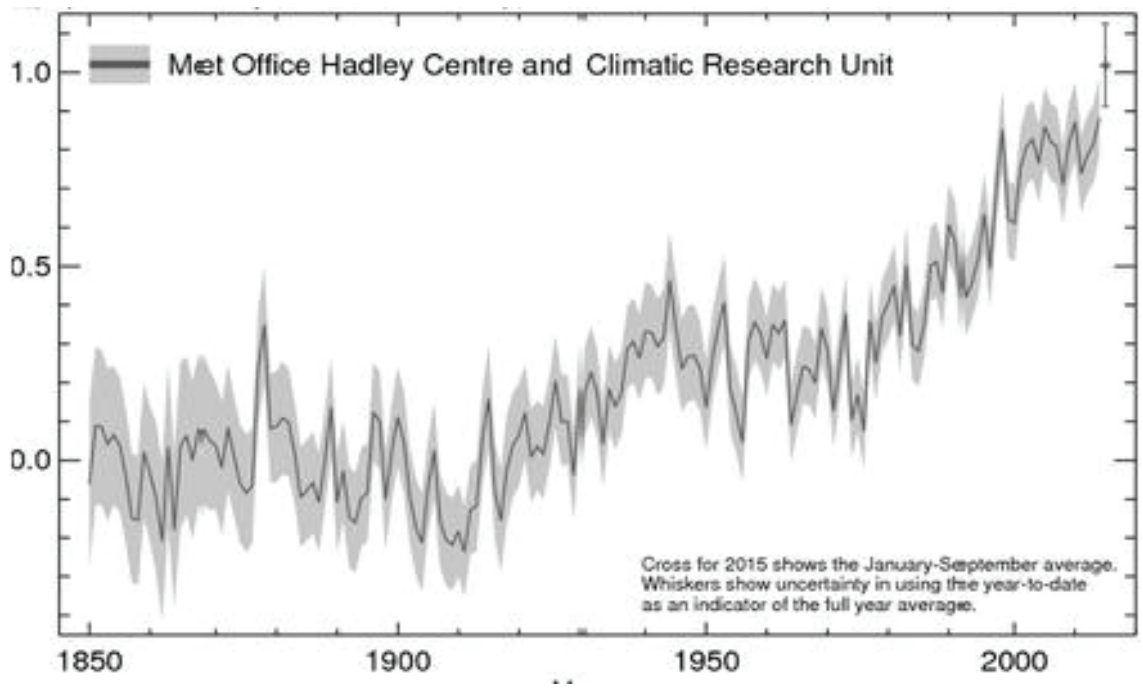

Ilustración 3. Temperatura promedio global (1850 - 2015)

Fuente: oficina meteorológica británica (Met Office). http://www.metoffice.gov. uk/research/news/2015/global-average-temperature-2015

Con $2^{\circ} \mathrm{C}$ de calentamiento se considera que, entre algunas consecuencias, partes del mundo serían inhabitables, habría peores sequías ${ }^{2}$ e inundaciones, fuertes tormentas, riesgo de que las zonas costeras se inunden, decrecimiento de ríos, expansión de desiertos, acidificación de los mares y ciudades afectadas ${ }^{3}$, inseguridad alimentaria por la disminución de rendimiento de cosechas y por la pérdida de hábitat por las inundaciones, colapso de la cadena de comida marina, pérdida de biodiversidad, y según Burke, Hsiang y Miguel (2015), el aumento de temperatura ensanchará más la desigualdad. Estas son algunas de las consecuencias previsibles, pero en general prima la incertidumbre sobre los efectos del cambio climático con sus consecuentes riesgos de que los sub o sobre-dimensionemos. Es decir, los promedios son engañosos; comprender el cambio climático es entender la enorme diversidad en la producción del problema y en el sufrimiento de sus efectos de forma

2 Por ejemplo, el segundo lago más grande de Bolivia, el lago Poopó de 2,337 km², se secó en 2015 debido a varias razones, entre ellas al fenómeno de El Niño, la contaminación minera y al desvío de afluentes (ríos) por productores del lado del Perú que usan sistema de riego. Ver: http://www.bbc.com/mundo/noticias/2015/12/151223_ciencia_bolivia_lago_poopo_ desaparicion_sequia_wbm. Otro ejemplo es la sequía en California (Estados Ünidos) entre 2012 y 2014, sequía considerada como la peor en 1200 años, ver: http://www.sciencedaily.com/ releases/2014/12/141205124357.htm

3 El siguiente estudio científico refiere que el nivel del mar puede subir más de $5 \mathrm{~m}$ y afectar a las ciudades como Londres, Miami, Shanghai y New York: (Hansen et al., 2015). 
diferenciada. Con caridad, claramente, no se resuelve la diversidad y la desigualdad que ello expresa.

\section{La contaminación en perspectiva histórica}

Al percatarnos de la gravedad de la situación del cambio climático (o calentamiento global) que amenaza la propia existencia humana, nos preguntamos cómo hemos llegado a este punto. La clave está en el aumento de los GEI provocado por las acciones humanas. Esto inició en el siglo XIX con la revolución industrial, primeramente con los países europeos, y luego incluyendo otros países más -he ahí los free riders mayores del mundo.

En el Cuadro 1 están los 14 países que más emitieron dióxido de carbono $\left(\mathrm{CO}_{2}\right)$ a la atmósfera en diferentes períodos históricos. Entre 1865 y 1890 los países de Europa (color azul) fueron los países que más contaminaron la atmósfera. Desde 1890 Estados Unidos aparece como el país más contaminador. Luego, entre 1960 y 1980 entraron cuatro países asiáticos en el grupo de los que más emitieron $\mathrm{CO}_{2}$. Y entre 1990 y 2012 hay un cuadro de 14 países más diverso y globalizado que más han contaminado. China a partir de 2005 se coloca como el país más contaminador.

Cuadro 1. Países emisores de dióxido de carbono en diferentes períodos históricos

\begin{tabular}{|l|l|l|l|l|l|l|l|}
\hline Rango & \multicolumn{1}{|c|}{1865} & \multicolumn{1}{|c|}{1890} & \multicolumn{1}{|c|}{1960} & \multicolumn{1}{|c|}{1980} & \multicolumn{1}{|c|}{1990} & \multicolumn{1}{|c|}{2005} & \multicolumn{1}{|c|}{2012} \\
\hline 1 & Reino Unido & EEUU & EEUU & EEUU & EEUU & China & China \\
\hline 2 & Alemania & Reino Unido & Rusia & Rusia & China & EEUU & EEUU \\
\hline 3 & EEUU & Alemania & Alemania & China & Rusia & Rusia & India \\
\hline 5 & Francia & Francia & China & Alemania & Japón & Japón & Rusia \\
\hline 6 & Polonia & Polonia & Reino Unido & Japón & Alemania & India & Japón \\
\hline 7 & Austria & Checoslovaquia & Ucrania & Reino Unido & India & Canadá & Irán \\
\hline 9 & Holanda & Rusia & Japón & Francia & Reino Unido & Reino Unido & Corea \\
\hline 10 & Checoslovaquia & Austria & Polonia & Canadá & Canadá & Corea & Canadá \\
\hline 11 & Italia & Canadá & Canadá & Polonia & Italia & Italia & Reino Unido \\
\hline 12 & Hungría & Italia & India & Italia & Francia & Irán & A. Saudita \\
\hline 13 & Suiza & Eslovaquia & Kazakstán & Kazakstán & México & Francia & México \\
\hline 14 & Canadá & España & Checoslovaquia & México & Australia & Australia & Indonesia \\
\hline
\end{tabular}

Fuente: basado en World Resources Institute

El Cuadro 1 ayuda a ver los 14 países que más emitieron $\mathrm{CO}_{2}$ en cada período. De forma acumulativa, la Ilustración 4 muestra a los países que más han contaminado entre 1850 y 2011. Ahí vemos que Estados Unidos ocupa el primer lugar con un 27\% de las emisiones. Le siguen 28 países de la Unión Europea con un 25\%. Luego están China, Rusia, Japón, India, Canadá, México, Brasil e Indonesia, 
que en conjunto emiten un 31\%. Finalmente está el resto del mundo (158 países) con un $17 \%$ del total de $\mathrm{CO}_{2}$.

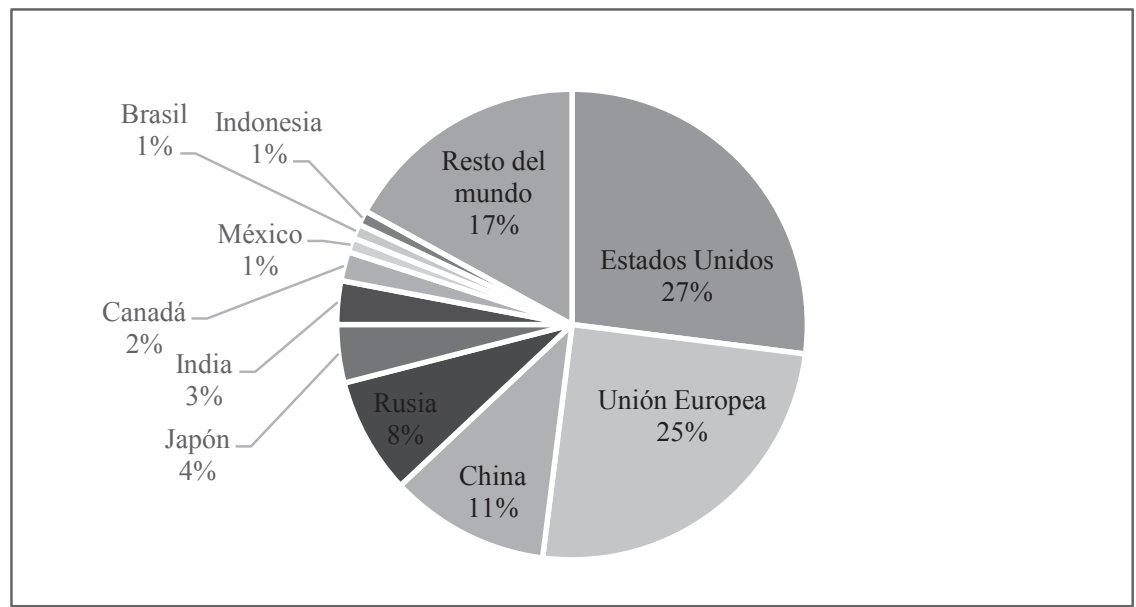

Ilustración 4. CO acumulado 1850-2011 (\% del total del mundo)

Fuente: basado en World Resources Institute. Ver: http://bit.ly/11SMpjA

Estos datos, sin embargo, ocultan la compleja interacción global que hay entre los países, los flujos y la externalización (outsourcing) de la polución. Por ejemplo países de Europa y de los Estados Unidos, para reducir sus emisiones de gas, demandan componentes de paneles de energía solar y de turbinas de viento fabricados en China ${ }^{4}$. Países como Inglaterra, para evitar multas de la Unión Europea que fija metas en reciclaje y porque los precios del plástico y papel bajaron, trasladan desechos reciclables a Indonesia ${ }^{5}$. O países como China que importa madera de América Latina para la construcción de gran cantidad de casas en tiempos de fuerte crecimiento económico. Tampoco aparece en los datos el flujo de las grandes corporaciones que se trasladan a otros países para desde allá exportar los productos que sus países necesitan. De este modo, países como China e Indonesia aparecen con mayor emisión de $\mathrm{CO}_{2}$, mientras países como Inglaterra aparecen con menos ${ }^{6}$.

Además del reconocimiento de vínculos de producción y consumo entre diferentes países, una vista hacia el uso de energía per cápita también influye en la interpretación del listado de contaminación. Para ello nos concentramos en el año 2013 y analizamos los seis países más contaminadores del mundo (ver Cuadro 2).

4 Ver: http://www.dailymail.co.uk/news/article-1241872/EXCLUSIVE-Inside-Chinas-secret-toxicunobtainium-mine.html

5 Ver: http://www.bbc.co.uk/news/magazine-21432226

6 En este contexto, la noción de "desigual intercambio ecológico" (unequal ecological exchange) revela que los países desarrollados externalizan sus costos basados en consumo hacia los países en desarrollo recrudeciendo su degradación ambiental. Ver: Jorgenson (2006). 
Cuadro 2. Países más contaminadores en la actualidad (2013)

\begin{tabular}{|l|l|c|c|c|}
\hline Rango & \multicolumn{1}{|c|}{ Países } & Población (\%) & $\begin{array}{c}\text { Consumo total de } \\
\text { energía (kilotones en \%) }\end{array}$ & $\begin{array}{c}\text { Emisiones de C02 } \\
\text { (kilotones en \%) }\end{array}$ \\
\hline 1 & China & 19.1 & 21.5 & 24.7 \\
\hline 2 & Estados Unidos & 4.4 & 17.2 & 16.2 \\
\hline 3 & India & 17.6 & 5.9 & 6.0 \\
\hline 4 & Rusia & 2.0 & 5.7 & 5.2 \\
\hline 5 & Japón & 1.8 & 3.6 & 3.5 \\
\hline 6 & Alemania & 1.1 & 2.5 & 2.2 \\
\hline & América Latina & 8.5 & 6.5 & 5.1 \\
\hline
\end{tabular}

Fuente: basado en World Resource Institute

El consumo total de energía está expresado en kilotones (1000 toneladas métricas) de los combustibles utilizados (relacionados con el petróleo, los del gas natural y los sólidos como el carbón); y la emisión del $\mathrm{CO}_{2}$ incluye la quema de combustibles fósiles, la manufactura de cemento y el dióxido producido por el consumo de gas natural y carbón. Del Cuadro 2 se observa que entre China, Estados Unidos, India y Rusia consumen la mitad de la energía generada en el planeta $(50.3 \%)$ y son responsables de la mitad de las emisiones mundiales de $\mathrm{CO}_{2}$ (52.1\%), pero a la vez son países que tienen el $43.1 \%$ de la población mundial. El gran desbalance lo expresa Estados Unidos al consumir $17.2 \%$ de energía y emitir $16.2 \%$ del total del $\mathrm{CO}_{2}$ cuando solo tiene el $4.4 \%$ de la población mundial, lo que de forma contundente evidencia que Estados Unidos, como país y en términos per capita, es el más contaminador de la atmósfera -el líder free rider.

A continuación mostramos dos gráficos que tienen que ver con el consumo de energía y la emisión de $\mathrm{CO}_{2}$ per capita, lo que debe ser interpretado con cierto cuidado. En el consumo de energía primaria antes de la transformación en otros combustibles finales (esto "equivale a la producción nacional más importaciones y variaciones de existencias, menos exportaciones y combustibles suministrados a barcos y aviones afectados por transporte internacional”) (ver Ilustración 5), entre los países más contaminadores están 6 países árabes (Qatar, Kuwait, Brunei, Bahrein, Omán y Emiratos Árabes Unidos).

En la emisión de $\mathrm{CO}_{2}$ (ver Ilustración 6) hay siete países árabes (Bahréin, Qatar, Kuwait, Emiratos Árabes Unidos, Brunei, y Arabia Saudita) entre los países más contaminadores. ¿Qué dicen ambos gráficos? Primero, por el tamaño de los países, estos gráficos no desdicen a los seis países más contaminadores del planeta. Segundo, el caso de los países árabes es algo particular, consumen más porque producen más combustible, y su dependencia del petróleo revela su real 'talón de Aquiles', porque la solución al cambio climático les significará experimentar la crudeza de la llamada "enfermedad holandesa".

Con datos de tendencias históricas de las emisiones de $\mathrm{CO}_{2}$ per capita a nivel nacional, basados en el consumo, Picketti (2015) confirma que las emisiones 
Encuentro №. 103, 6-27, 2016

globales están concentradas: 10\% de los emisores globales (de todos los continentes) contribuyen con el 45\% de las emisiones globales, y el 50\% de los que menos emiten contribuyen con el 13\% de las emisiones globales.

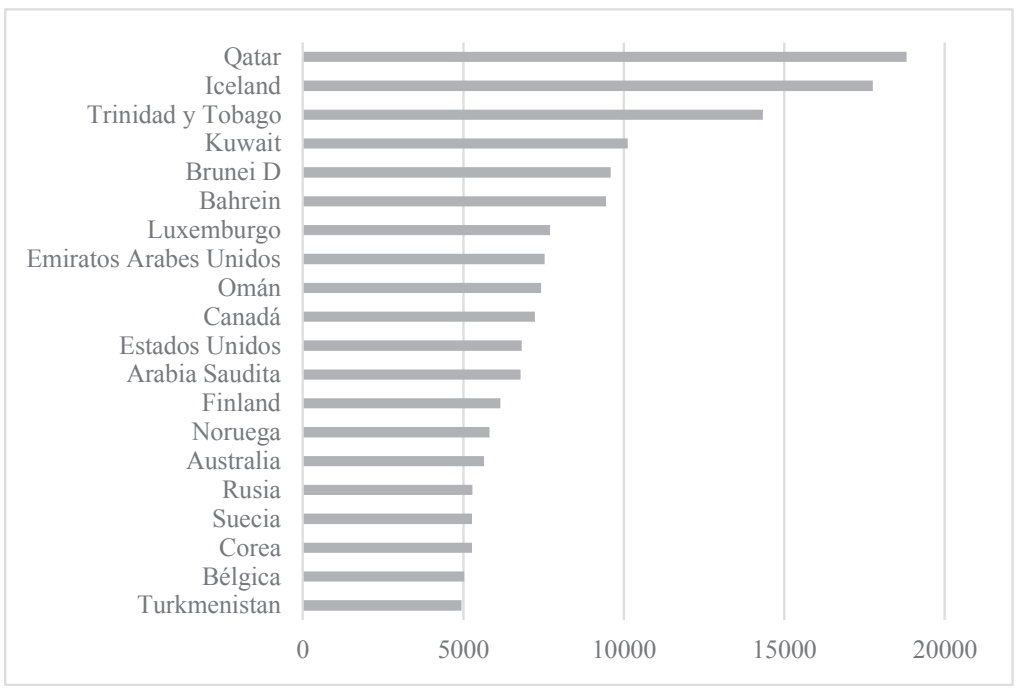

Ilustración 5. Uso de energía (kg equivalente de petróleo por cápita) (2012) Fuente: basado en Agencia Internacional de la Energía, http://www.iea.org/stats/ index.asp. También: http://datos.bancomundial.org/indicador/EG.USE.PCAP. KG.OE

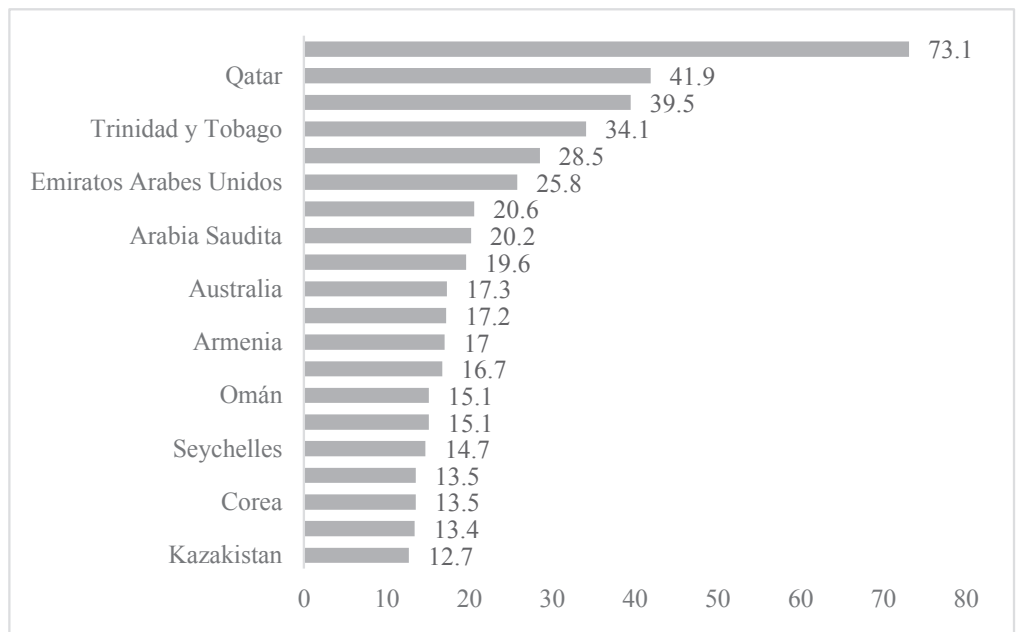

Ilustración 6: emisión de CO2 (ton métricas per capita) (2014)

Fuente: basado en la División de Estadísticas de las Naciones Unidas. Ver Gráfico en: http://www.tsp-data-portal.org/TOP-20-CO2-emitters-per-capita\#tspQvChart 
Para complementar esta descripción de la contaminación, indicamos sus fuentes también por sector (ver Ilustración 7). La fuente de mayor contaminación es la producción de energía (44\%) que incluye uso de electricidad, uso industrial de energía y otras fuentes relacionadas a la energía; seguida por agricultura y deforestación (26\%); después los procesos industriales y desechos, y quema de combustible en casas residenciales y comerciales (16\%); y transporte (14\%).

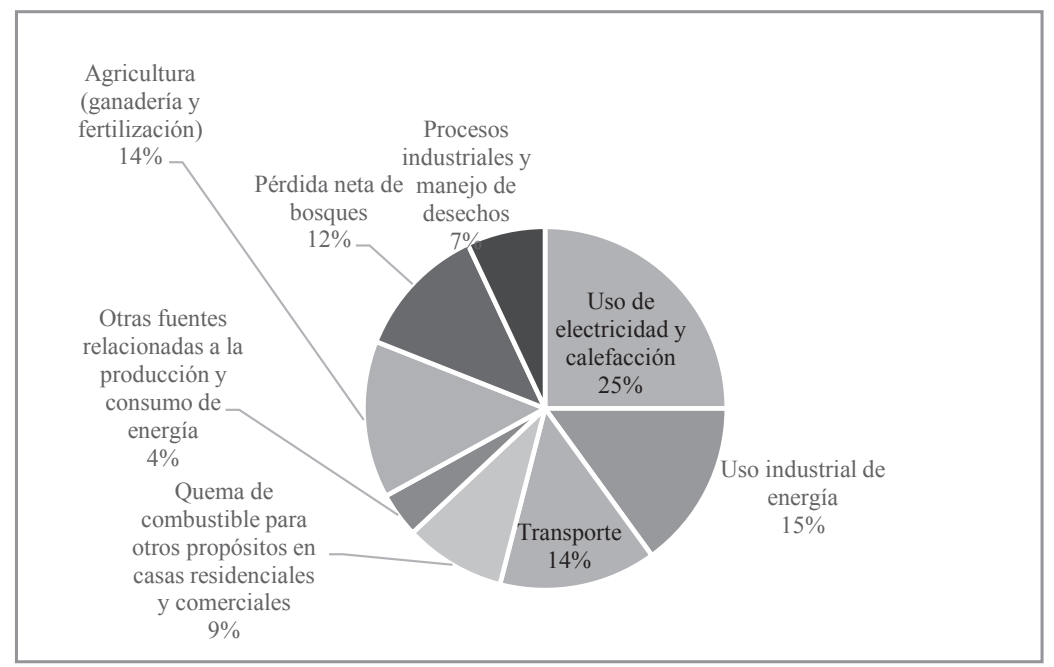

Ilustración 7. Emisiones globales de gasesde efecto invernadero (2011-2012)

Fuente: Schwabish, N. Tawil y C.ourtney Grith, 2012, Congressional Budget Oce basado en información del Banco Mundial, World Resources Institute; Resources for the Future and Climate Advisers, y LTS International. Ver: https://www.cbo.gov/ sites/default/files/112th-congress-2011-2012/graphic/1-6-12-forestinfographic0.pdf

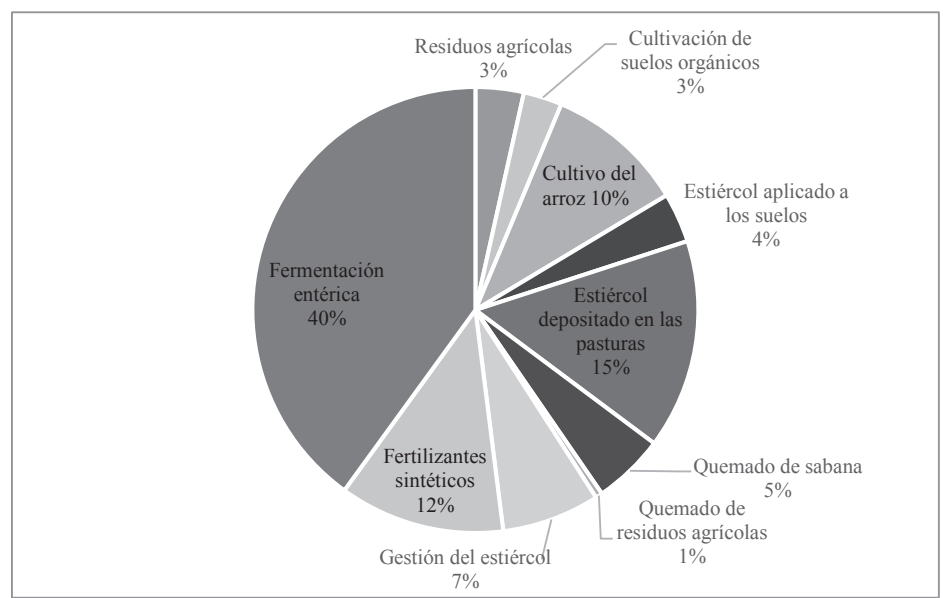

Ilustración 8. Emisiones de gases por efecto invernadero, por sector de la agricultura (promedio 1990-2012

Fuente: FAOSTAT http://faostat3.fao.org/browse/G1/*/S 
Y dado que la agricultura nos interesa por su histórico peso en el mundo, en particular en América Latina, incluyo la Ilustración 8. Del total de la contaminación generada por agricultura, 36\% viene del óxido de nitrógeno $\left(\mathrm{N}_{2} \mathrm{O}\right), 14 \%$ de $\mathrm{CO}_{2}$ y $50 \%$ del metano $\left(\mathrm{CH}_{4}\right)$. De ese $100 \%$, la mayor contaminación viene de la ganadería: $40 \%$ de la fermentación entérica (digestión de material orgánico de parte del ganado) y 15\% del estiércol depositado en las pasturas (también ver: Reynolds (2013).

Resumiendo lo visto hasta aquí, el calentamiento global se ha dado por el aumento de los GEI, aumento que se ha debido mayormente a la generación de $\mathrm{CO}_{2}$ (además de metano y óxido de nitrógeno) en el que Estados Unidos y Europa de forma acumulativa han emitido el $52 \%$ del $\mathrm{CO}_{2}$. Seis países son los que más contaminan en términos absolutos y relativos. Resalta también las estrategias de algunos países para aparecer como menos contaminadores. El caso de los países árabes, con alto consumo per capita por su producción de combustible barato, es caso particular por estar enfrentadas al dilema de contribuir a salvar el planeta (dejar los combustibles fósiles bajo tierra) y su sobrevivencia debido a su dependencia del petróleo. Finalmente la contaminación según sector revela a la agricultura y al sector forestal, con 14 y $12 \%$ respectivamente, con un porcentaje no alto, pero que son sectores muy importantes porque: allí se concentra la mayor parte de la población empobrecida; es el único sector con potencial de absorber los GEI de la atmósfera; y porque la agricultura es un sector que mayor contribución puede proveer en la mitigación del cambio climático (Reynolds, 2013) al igual que el sector forestal. Esto último es refrendado por la experiencia del Brasil, país que redujo en un $70 \%$ la deforestación en la amazonia entre 2005 y 2013, y con ello ha tenido directo efecto en las emisiones a nivel mundial ${ }^{7}$, sin cuya contribución la Ilustración 7 sería diferente y el gasto del presupuesto de carbono sería mayor para el 2012 en la Ilustración 2. Concluyendo, la agricultura es otro caso que muestra la importancia de la diversidad, y ello nos dice que la pobreza y la desigualdad pueden resolverse si la agricultura y lo forestal contribuyen efectivamente, con prácticas e institucionalidad innovativas, a absorber los GEI.

\section{Acuerdos de París y sus alcances}

196 miembros (195 países y la Unión Europea) llegaron a un acuerdo "legalmente vinculante”, que será ratificado en abril de 2016 y entrará en vigor en 2020. Las palabras clave del acuerdo son: mitigación, adaptación, financiamiento, tecnología y construcción de capacidades. El principal objetivo de los acuerdos es: mantener el aumento de la temperatura global por debajo de $2^{\circ} \mathrm{C}$ con respecto a los niveles pre-industriales "y de seguir esforzándose por limitar el aumento de la temperatura a $1,5^{\circ} \mathrm{C}$ ". Para ello, 162 países han entregado su hoja de ruta llamada "contribución

7 En 2004 el presidente Lula Da Silva prometió una política de reducción del $80 \%$ de la deforestación. Nepstad et al (2014) da cuenta de ello, que entre 2005 y 2013, disminuyó el $70 \%$ de la deforestación en la Amazonia brasileña, lo que evitó la emisión a la atmósfera de 3.200 millones de toneladas de dióxido carbono, y que en tan sólo 2013 representó una reducción del 1,5\% en las emisiones globales. Ver también The Economist: http://www.economist.com/news/scienceand-technology/21603409-how-brazil-became-world-leader-reducing-environmental-degradationcutting 
nacional determinada" (Intended Nationally Determined Contributions, INDC) para limitar los efectos del aumento de la temperatura, mientras nueve países, entre ellos Nicaragua, no entregaron sus INDC ${ }^{8}$, y otros países, como Bolivia, entregaron su INDC condicionando al financiamiento externo9; acordaron movilizar 100 mil millones de dólares anuales desde los países desarrollados a los países en desarrollo, como mecanismo de financiación para medidas de mitigación y adaptación al cambio climático $^{10}$; y acordaron apoyo a la investigación, el desarrollo y la demostración de tecnologías, y el desarrollo y la mejora de las capacidades y tecnologías endógenas. Las áreas priorizadas para la reducción de los gases de efecto invernadero son energía renovable, eficiencia energética, transporte, metano y agricultura y sector forestal.

El ruido generado en torno al acuerdo de París es de triunfalismo, pero la realidad parece ser más dura. Recordemos que el tema del cambio climático ya fue discutido en la Cumbre de la Tierra de Río en 1992, evento en el que se conoció los tratados sobre la Convención Marco de las Naciones Unidas sobre el Cambio Climático (CMNUCC), de la Diversidad Biológica y Convención sobre la Lucha contra la Desertificación. Observemos, para 1990 habíamos gastado 43.4\% del presupuesto de carbono y para 2012 gastamos 67.1\%; si los gobiernos hubiesen decidido combatir el cambio climático en 1992, la situación de hoy en día sería muy diferente. Incluso, $1.5^{\circ} \mathrm{C}$ podía lograrse si hubiese habido un acuerdo en la primera Conferencia de las Naciones Unidas en Berlín 1995, mientras ahora es solo "una aspiración y una meta improbable" (Monbiot, 2015). A 23 años de la Cumbre de Río y a 20 años de la Conferencia de Berlín, y con el calentamiento global al doble del de 1990, de cumplirse los Acuerdos de París solo se logrará que el aumento del calentamiento global sea más lento y que no pase más allá del año 2080. Peor aún, dichos acuerdos jrecién van a aplicarse a partir del 2020!

Algo más: primero, de llevarse a cabo dichos acuerdos, el 100\% del presupuesto de carbono será gastado hasta el año 2050, en lugar de que se gaste para el año 2033; aun así la contaminación seguirá y el gasto del presupuesto será del 107.3\% en 2080 (Ilustración 2), año a partir del cual la situación mejoraría y en el año 2200 el gasto del presupuesto de carbono será del $95.8 \%$, jun nivel muy por encima del presente! Segundo, los Acuerdos de París advierten que los INDC enviados por los países significan emisiones agregadas de gases de efecto invernadero que sobrepasan los $2^{\circ} \mathrm{C}$ y "conducen a un nivel proyectado de 55 gigatoneladas en 2030", mientras el reto es 40 gigatoneladas "para mantener el aumento de la temperatura media mundial por debajo de $2^{\circ} \mathrm{C}$ " con respecto a los niveles preindustriales; las 55 gigatoneladas implican un aumento de temperatura de $2.7^{\circ} \mathrm{C}$ expresado en la Ilustración 1 .

8 P. Oquist (ver: https://www.youtube.com/watch?v=uL53JDkek2g) justificó el que Nicaragua no haya entregado: que las Naciones Unidas, para efectos del cambio climático, carece de mecanismos de verificación objetiva de la expresión de voluntades individuales de los países; y porque Nicaragua tiene baja emisión y que además lo está reduciendo -en 2014 solo emitió 0.03\% de gases, y que por el aumento de energía renovable (de 25 a 52\%) el país ahorró 2.1 mill. tons de $\mathrm{CO}_{2}$, con lo que el total de emisión de gas bajó a 4.8 millones de toneladas.

9 Ver: http://www.c2es.org/international/2015-agreement/indcs

10 Este financiamiento ya había sido aprobado en 2011 como Fondo Verde para el Clima (GCF, por sus siglas en inglés), como mecanismo financiero de la Convención Marco de Naciones Unidas sobre el Cambio Climático (UNFCCC, por sus siglas en inglés). Ver: http://finanzascarbono. org/financiamiento-climatico/canales-bilaterales-de-financiamiento/fondo-verde-para-el-clima/ El Acuerdo de París ratifica ese acuerdo. 
Tercero, la euforia de haber llegado a un acuerdo mundial hace olvidar que aun esos $2^{\circ} \mathrm{C}$ es "temperatura media mundial", lo que en los países tropicales será mayor, y ello significa que los Acuerdos de París son, en el fondo, una aceptación parcial de esa calamidad.

Estos resultados hacen que J. Hansen, considerado el padre de la conciencia global sobre el cambio climático por ser el primer científico en alertar sobre este problema en 1988, califique los Acuerdos de París como "un fraude" y "una falsedad" (Milman, 2015). ¿Por qué? Hansen argumenta que los acuerdos solo son "promesas sin acciones”, que mientras no se fijen impuestos (o cargos) a las emisiones de gas, el cambio climático empeorará. De forma más moderada, Monbiot (2015) dice que los Acuerdos de París, comparados con lo ocurrido en Copenhagen en 2009, en que no llegaron a acuerdos y visto desde el "marco estrecho" de las Naciones Unidades, son "un milagro" ${ }^{11}$; mientras visto desde fuera de ese "marco" de las Naciones Unidas, desde lo que debería ser, "es un desastre".

\section{La corriente debajo de las olas del mar}

¿Por qué es tan difícil ponerse de acuerdo para salvar al planeta? Es el dilema de la acción colectiva. Por los datos vistos, los acuerdos dependen en gran medida de que los diez países que más han contaminado - o las empresas que están detrás de ellos - cedan en sus posiciones y superen lo que Hardin llamó "tragedy"; de que los países que no están en esa lista - y también las compañías y sus contrapartes nacionales -, al ver que su ruta de desarrollo vía industrialización tiende a ser limitada, igualmente cedan a una perspectiva de diversidad; y por lo observado en diferentes partes del mundo, depende también de la creciente conciencia y movilización social reactiva ${ }^{12}$ y sobre todo proactiva y con pensamiento de largo plazo.

La "corriente debajo de las olas del mar" tiene que ver con las ideas y los intereses. Monbiot (2015) identifica "un marco estrecho" en el que se han dado las discusiones sobre el cambio climático. Verbruggen (2015) dice que hay una gran coalición sobre el clima (oficiales, académicos, capitanes de industrias y personas que hacen campaña verde) enraizada en la creencia de que "no hay alternativa" y en una fe de que "la única forma viable es seguir el curso actual", lo que no parece ser apropiado en un tema como el cambio climático donde se experimenta disrupciones frecuentes y que requeriría de diversas teorías, prácticas y tecnologías. Ese "marco estrecho" y "la única forma viable" es la perspectiva económica, y esa "gran coalición" en realidad son los technopols que Robinson (2003, pp. 214-217) ha identificado en cada país, que son determinados intelectuales "carismáticos, orgánicos, politizados y organizadores locales de grupos con orientación transnacional que juegan un importante rol distinguiendo estrategias locales, programas políticos, planes técnicos

11 Para leer la cronología sobre el cambio climático, ver: http://www.un.org/climatechange/es/ hacia-un-acuerdo-sobre-el-clima/. Para un recuento histórico de la "ola" (Acuerdos de París) y en particular el día a día de las negociaciones en Paris, ver Campos (2016).

12 Ha habido muchas protestas y luchas en todos los países del mundo. Para una muestra, ver resumen del movimiento Avaaz https://secure.avaaz.org/es/climate_story_loc/?beAxNab\& $v=70850 \&$ cl=9162323010 y el Run for your life, con Jenni Laiti: https://www.youtube.com/ watch?v=7ZR6kGNM_LO 
e ideologías, para la integración en el nuevo orden global”. Son actores conectados entre sí, nacional e internacionalmente, que penetran el Estado y promueven el proyecto transnacional de globalización capitalista. Verbruggen cuestiona por qué los economistas abrazan un enfoque global único (de mercado) en política climática, cuando se ha tenido tantos fracasos pretendiendo imponer una "camisa de fuerza uniforme", y acusa a esa perspectiva de haber paralizado la política climática desde 1997 en COP03 Kioto cuando Estados Unidos impuso el comercio de emisiones ${ }^{13}$.

Esa perspectiva, motivada por intereses económicos de los países, ha llevado a que los Acuerdos de París estén enfocados al consumo de combustibles fósiles y no a su producción (Monbiot, 2015) y que sean promesas fáciles de ser burladas por los países. Un ejemplo de esta última lo revela Inglaterra, un país que tiene una política para reducir las emisiones de gases de efecto invernadero (reducir demanda de combustibles fósiles) bajo la ley del Cambio Climático 2008 (en coherencia con los Acuerdos de Kioto) y otra política bajo la ley de Infraestructura 2015 con el que urge a las compañías de petróleo y gas a aumentar su producción (mayor emisión de gases de efecto invernadero) para "maximizar la recuperación económica" de Inglaterra (Monbiot, 2014). Por un lado reduce las emisiones de gas y por el otro lado incentiva a aumentar su emisión, y ambas políticas son ejecutadas bajo la dirección del Ministerio de energía y cambio climático (Secretary of State for Energy and Climate Change). Lo que pasa en Inglaterra, el mismo Monbiot lo confirma, es una práctica común de los gobiernos atrapados en los intereses de las grandes corporaciones.

Desde el lado de algunos gobiernos de países en desarrollo hay críticas al sistema capitalista, pero sin salirse del "marco estrecho". Correa (2015), presidente del Ecuador, señala que la vieja división del trabajo, de países productores de materia prima y países encargados de la industrialización de esa materia prima, ha sido sustituida por otro: "los países ricos generan conocimiento -ciencia, tecnología- que privatizan, mientras países como Bolivia, Venezuela, Ecuador, países de la cuenca amazónica, generamos bienes ambientales que ellos consumen gratuitamente..." Correa señala que ese conocimiento es privatizado a través de "patentes" y "regalías", y cuya violación es penada con cárcel, mientras "no hay cárcel si una transnacional destruye nuestra naturaleza”. Esa nueva división del trabajo, según Correa, se basa en el "poder": "¿Quiénes son los contaminadores, pero que producen conocimiento que privatizan y en cambio consumen bienes ambientales libremente? Son los más poderosos"; "hay tribunales para la deuda financiera, hay tribunales para proteger, no los derechos sino muchas veces los abusos de las transnacionales. ¿Por qué no hay tribunales para algo tan fundamental como establecer la deuda ecológica...?" Por su lado, Evo Morales, presidente de Bolivia, en la 70 Asamblea General de las Naciones Unidas, dijo que los países del sur no van a ser "los guardabosques de los países del sistema capitalista". Y en la misma COP21 de París, el representante de

13 El Protocolo de Kioto de 1997 vincula jurídicamente a los países desarrollados a los objetivos de reducción de emisiones. Se fija metas de reducción de gases de efecto invernadero de $5 \%$. Período de compromiso 2008-2012, y 2013-2020. Ese acuerdo solo lo firmaron 37 países (28 países de Europa). El Congreso de los Estados Unidos no lo ratificó y países como china, uno de los países con más emisiones, quedaron fuera. Para 2015, los 37 países firmantes lograron reducir $22 \%$ de las emisiones. 
Nicaragua, P. Oquist expresó: 1) que los acuerdos reconozcan el endeudamiento de los países históricamente responsables por el cambio climático; 2) que bajo el principio de responsabilidad indemnicen a los países en desarrollo en tanto las consecuencias del cambio climático lo sufren más los países en desarrollo; 3) que la meta promovida por los países en desarrollo, particularmente los estados isleños, ha sido de $1.5^{\circ} \mathrm{C}$ y no $2^{\circ} \mathrm{C}$, y que los países más contaminadores reduzcan sus emisiones de gas; y 4) que el procedimiento para la decisión de los Acuerdos fue autoritario y no democrático ${ }^{14}$.

A la vez, en aparente contradicción, Correa apoyó la explotación petrolera en el parque amazónico Yasuni y en otras comunidades indígenas (Sarayaku, Kichwa, etc). Igual situación se da en el caso de Bolivia, Venezuela y otros países. El discurso hacia fuera no parece estar refrendado al interior de sus países. Esto se debe a tres razones. Primero, sus políticas ambientales no están respaldadas de recursos propios, ya que son dependientes de recursos externos llámense 'indemnizaciones' o Pagos por Servicios Ambientales (PSA), por lo que terminan aceptando las políticas ambientales gobernadas por los mercados $^{15}$. Segundo, persiste el viejo modelo de organización taylorista en que se han formado los estados, partidos políticos, sindicatos y guerrillas, estructuras de vanguardia, que les impide ir y escuchar a las comunidades y tomar en serio sus perspectivas que van más allá de la economía y sus rutas que transitan fuera de la linealidad definido por la teoría de la modernización sobre el 'desarrollo'. Tercero, al criticar la ausencia de responsabilidad de los países desarrollados y a la vez reclamar por indemnizaciones, están negando la diversidad en el mundo sobre la que justamente suelen hablar de forma discursiva. Como dijimos antes, con caridad no se resuelve la diversidad y las desigualdades.

Esa lógica económica, llamada por Polanyi décadas atrás como "sociedad de mercado", pospone acuerdos y su cumplimiento, desvía la atención hacia la demanda mientras rechaza dejar los combustibles bajo tierra, critica la emisión de gases en un país y a la vez abre las puertas a las compañías extractivas. Esa oposición, exitosa desde al menos la Conferencia de las Partes de Berlín 1995 permitió que se dieran los Acuerdos de París como "consenso". Bajo esa lógica, el progreso (económico) de los países ha caminado incrustado en la emisión de gases. Es la idea de que no hay desarrollo sin industrialización, que el cambio climático se resolvería con más progreso económico (y "ayuda”), que no es con menos mercado que el cambio climático va a resolverse sino con más mercado. En coherencia con esta forma de pensar, cualquier país - mejor dicho las corporaciones detrás de los gobiernos- teme que aceptar regulaciones ambientales le signifique perder sus ventajas competitivas ante sus competidores o, en el caso de los gobiernos de países en desarrollo, temor a no recibir recursos externos calificados por muchos de ellos como "indemnizaciones",

14 Ver: https://www.youtube.com/watch?v=uL53JDkek2g. Para mayor lectura sobre el planteamiento del gobierno de Nicaragua publicado antes de la Cumbre de París, ver: Oquist (2015).

15 Van Hecken, Bastiaensen y Huybrechs (2015) discuten sobre la "circulación epistémica" para explicar cómo los países miembros del ALBA (Alternativa Bolivariano) se confrontan a las políticas ambientales conservacionistas y luego terminan sumándose a ellas. Los autores observan, en el caso de Nicaragua, cómo a pesar de la perspectiva crítica del gobierno sobre los pagos por servicios ambientales (PSA), la mayoría de los proyectos PSA en el país han sido llevados a cabo respondiendo a la perspectiva dominante de ser gobernados por el mercado. 
"inversión extranjera" (corporaciones extractoras de recursos naturales con emisión de gases de efecto invernadero) como derecho ante el "imperialismo". Las "olas" del Acuerdo de Paris hacen que nos movamos "surfeando" a los grandes contaminadores que aparecen como los salvadores del planeta y como los financiadores de los países en desarrollo para adaptarse al cambio climático. La "resaca” es que los países en desarrollo serán los más afectados aun por el mismo Acuerdo de París. Tendrán que sacrificar el tipo de futuro (camino de la industrialización) que han ido buscando, emulando a los países desarrollados; mientras los países desarrollados seguirán su camino de progreso con emisión de los GEI.

Más que lo anterior, la "corriente de agua" hay que captarla desde una perspectiva histórica. Moore (2015) hace referencia a dos mitos. Primer mito: que la causa del cambio climático comenzó con la industrialización en Inglaterra de 1800, un mito compartido también por el pensamiento de los movimientos ambientalistas o el llamado enfoque de "la economía verde". Moore argumenta que el capitalismo surgió en el s. XV, XVI y XVII, período (1450-1750) de la más grande revolución ambiental en que los paisajes naturales y los humanos en esos paisajes fueron sometidos. La expresión más dramática de ese proceso fue la conquista de América en términos militares, de genocidio humano y ambiental. Es decir, se impuso con las plantaciones de azúcar y luego con las minas de plata en Potosí, apropiándose de forma gratuita (o a bajo costo) del trabajo de la naturaleza y de los -considerados"no-humanos" indígenas y esclavos. Ese proceso destruyó montañas de bosques y erosionó tierras de la zona de los Andes. Ese sistema continuó con el extractivismo y el monocultivismo de la caña de azúcar, tabaco, algodón... combustible... El patrón ha sido el mismo: conseguir nueva forma de naturaleza que trabaje gratis y a bajo costo laboral. Desde esta perspectiva, la idea de los países desarrollados en París 2015 fue expresada como "consenso" porque "el resto" de países con sus propuestas no contaban, igual que antes cuando las poblaciones indígenas, los esclavos y la naturaleza eran vistos como partes de la naturaleza, como "los naturales".

El segundo mito es que los problemas creados por el capitalismo son responsabilidad de toda la humanidad o que el cambio climático es responsabilidad de todos. Moore (2015) califica ese mito como "de visión racista, eurocéntrica y patriarcal”. Hay responsabilidades históricas ante el cambio climático, injusticia que es escondida por los Acuerdos de París. No es tanto de "indemnizaciones", sino de que el sistema capitalista deje de alimentarse de lo que la naturaleza produce, del trabajo barato, de la energía, comida y materia prima baratos, deje de persistir basado en genocidio humano y ambiental. De aquí, el mayor riesgo es que los Acuerdos de París sean una puerta al despojo mercantilizando la naturaleza, en un contexto en que las oportunidades de apropiarse de trabajo gratuito del bosque, océanos, clima y del suelo es cada vez menor.

De lo anterior, en sintonía con Moore (2015), pasamos a ver la realidad sin separar lo económico y lo social de lo ecológico, como la historia del surgimiento del capitalismo lo revela y como lo vemos en las zonas secas de América Central y América del Sur. Esto abre nuevas ventanas de comprensión de la realidad combinando cambio climático y desigualdad de raza y género. Este paso, a su vez, nos permitiría realizar nuevas alianzas entre organizaciones de productores, organizaciones feministas, organizaciones de trabajadores y organizaciones estudiantiles. 


\section{Desafíos}

Antes de seguir, recapitulemos lo trabajado hasta aquí a la luz del marco teórico propuesto. El clima es un bien colectivo, cuya 'sobre-explotación' se debe al oportunismo (free riding) de, mayormente, grandes corporaciones y países desarrollados que han contaminado la atmósfera. Este hecho se ha sostenido no solo a lo largo de 200 años (revolución industrial) sino de más de 500 años bajo la emergencia y consolidación del sistema capitalista sobre la base del trabajo barato de la naturaleza y de la mayoría de la población mundial, lo que ha conllevado también la institucionalización de un patrón de organización excluyente. Estas estructuras se han expresado en ideas basadas en el fundamentalismo del mercado, en la creencia de que no hay alternativa, y con efectos de "resaca".

Esta perspectiva ha generado una tesis pesimista y conservadora, de que los causantes del problema difícilmente van a cambiar y que no hay mayor fuerza humana capaz de hacerlos cambiar. Es pesimista en el sentido que, si resulta cierta, el planeta se volverá menos habitable en la segunda mitad del presente siglo. Y es conservadora en tanto que genera impotencia, de que no hay mucho que hacer, de que el problema es tan complejo que ni sabemos qué hacer.

Sin embargo, discernir los factores estructurales, apoyados por una perspectiva histórica, permite avizorar una tesis más optimista de cambio institucional, de una nueva y más transformadora correlación de fuerzas. Esto es, una "sociedad en movimiento" con conciencia mundial -de presión y también con decisión de, por ejemplo, reducir su consumo de carne, leche y energía- de entender la realidad social, económica y ecológica como partes de un mismo proceso, conectada con las familias de pequeños productores (campesinos e indígenas) con prácticas sostenibles inteligentes en el uso eficiente del suelo y forestería, con el re-impulso de un sector empresarial en torno a nuevas tecnologías de cambio de la matriz energética, con científicos comprometidos en hacer que las energías renovables resulten más baratas que la energía proveniente del carbón, gas y aceite ${ }^{16}$, y con gobiernos que promuevan regulaciones fiscales apropiadas para incentivar la energía renovable y -siguiendo a Piketti (2015) - aplicar impuestos a los más ricos tanto en los países desarrollados como en los países en desarrollo, superando el dualismo tradicional norte-sur. Esta correlación de fuerzas podría hacer retroceder a la vieja y dominante correlación de fuerzas dirigida por las corporaciones, y sería una ventana de posibilidades para la transformación social, política, económica y ecológica de nuestras sociedades y sus instituciones en este planeta tierra.

Bajo este marco, a continuación listamos tres desafíos. El primer desafío es proveer soluciones que hagan posibles los Acuerdos de París con una perspectiva que a la larga permita dejar los combustibles bajo el suelo. Es claro que llegar a

16 Siete científicos y economistas de Inglaterra han propuesto un programa de investigación tipo Apolo, con el propósito de hacer investigación que en diez años produzca energía renovable y limpia más barata y libre de la emisión de $\mathrm{CO}_{2}$. Esa energía estaría basada en 3 pilares: renovable (especialmente solar y eólica), poder nuclear y 'captura de carbono'. Lo hacen bajo la idea de que para 2025 garanticemos que el calentamiento global esté debajo de $2^{\circ} \mathrm{C}$, de lo contrario consideran un cambio climático catastrófico. Ver: King, et al. (2015). 
estos Acuerdos ha tomado mucho tiempo, las metas actuales son insuficientes para salvar al planeta, y la manera que proponen para llegar a reducir el $\mathrm{CO}_{2}$ es con una visión productivista y de "economía verde". Para introducir políticas y decisiones que hagan posibles los Acuerdos de París, es necesario comprender la crisis económica, la crisis social y la crisis ecológica como crisis del capitalismo; al hacerlo, sustituir el fundamentalismo económico en el que estamos atrapados por una perspectiva más integral de vida. Sin salir de esa trampa, aun las soluciones como el de energías limpias (la solar, geotérmica, eólica y demás) no prosperarán, igual que las perspectivas críticas de los gobiernos de países miembros del ALBA, que con o sin recursos propios siguen sin salir del fundamentalismo económico.

El segundo desafío es evitar que el capitalismo use los Acuerdos de Paris como puerta de entrada para acumular más en base a su práctica histórica de apropiarse de la naturaleza y trabajo baratos. Parte de esa realidad lo hemos observado en las políticas de áreas protegidas en América Latina, igual que en muchos casos la titulación de territorios indígenas, que han servido para despojarles de sus tierras a las poblaciones indígenas y afro-descendientes, y a las familias campesinas ${ }^{17}$. Y parte de esa modalidad es dar migajas a los países en desarrollo como licencia para seguir generando GEI, migajas que llegarían amarradas a mecanismos de 'gestión por resultados' ${ }^{18}$ con lógica individualista (p.ej., al productor individual por sembrar árboles en sus fincas) y erosionando las expresiones organizativas (cooperativas, asociaciones y organizaciones comunales) que particularmente las sociedades rurales tienen para resistir a los mecanismos de despojo de parte de las grandes empresas que están siempre listas para comprarles tierras. Esto es una forma de despojo que desfavorece no tanto a los países en desarrollo sino al $80 \%$ de la población mundial que solo accede al $17.2 \%$ de los ingresos mundiales ${ }^{19}$.

El tercer desafío es superar el dualismo naturaleza/sociedad desde los mismos actores considerados históricamente como "naturales", las familias campesinas, indígenas y afro-descendientes. La cuestión del cambio climático tiende a aparecer como algo muy complejo que deja un sentido de impotencia en las personas, de hacer sentir que las acciones humanas de cambio son tan pequeñas ante algo tan grande como el cambio climático. Y esa 'campaña' ideologizada y sesgada sobre el cambio climático ha hecho que las familias indígenas y campesinas tiendan a "auto-culparse" por el cambio climático, algo contrario a lo indicado en la Ilustración $7^{20}$. Ese

17 El despojo lo implementan no solo las compañías extractivas y empresas de monocultivo, también las instituciones que nacieron como alternativas. Por ejemplo, muchas microfinancieras presentan sus carteras como "crédito verde", el cual, financiando la ganadería extensiva contribuyen más bien a ese despojo de tierras y territorios; esas mismas microfinancieras no dan crédito ni a las poblaciones indigenas ni a las familias campesinas que diversifican su producción y que se hallan en las áreas protegidas y territorios indigenas. O cooperativas que tienen áreas de bosque y que están impedidas de tocar un solo árbol.

18 Para una perspectiva crítica, ver: Chambers (2014).

19 Datos para 2007 tomados de: Ortíz y Cummins (2012).

20 En un taller con mujeres y hombres líderes de organizaciones rurales (enero 2016), y de representantes de instituciones académicas y empresariales, la perspectiva de ambos grupos se expresó diferente. El primer grupo, de las y los líderes, era de culparse a sí mismo sobre el cambio climático, atribuyendo las causas a las "malas prácticas en la producción", "quema y despale", "uso de químicos en agricultura" y a la "falta de educación en las familias"; mientras el segundo grupo atribuyó las causas al "pensamiento de corto plazo", a "las Compañías" y a "la dependencia en el petróleo". 
grado de complejidad y de inseguridad que el cambio climático genera, combinado con auto-culpa de parte de las familias campesinas, puede ser contraproducente. Enfrentar esta situación requiere que superemos la idea de que solo por la vía de la industrialización se puede lograr el desarrollo, mostrar que la vía campesina, indígena y afro-descendiente, un camino de resistencia de siglos ante el capitalismo, en alianza con diversos actores, puede mitigar el cambio climático, y en ello el rol de la agricultura y lo forestal para absorber los GEI, mencionados antes, hacen ver al mundo la importancia de ese sector social campesino e indígena.

\section{Perspectiva desde las familias campesinas, indígenas y afrodescendientes}

¿Cómo asumir los desafíos y mitigar el cambio climático? Las estrategias de diversificación de estas familias - con sus variantes entre una y otra (ver Mendoza, 2004) - contrarias al sistema de monocultivo y al extractivismo, e incluyendo la organización familiar y territorial apostando por la vida conectada a la tierra, son ángulos y prácticas diferenciadores para mitigar el cambio climático.

Desde esta perspectiva de diversidad, territorios, diversificación, organización y vínculo con la tierra, y en contra de los technopols identificado por Robinson (2003), proponemos la construcción de una "comunidad epistémica" que, en palabras de Marchetti (2015, p.20), es "continuo y más profundo encuentro de diversas maneras de saber cruzando aspectos educacionales y geográficos, abandonando recetas externas, el canon externo de la ciencia e incluso el canon externo de políticas sobre clima-energía, y responsabilizándose de formular y ajustar políticas cada año en diferentes geografías y comunidades epistémicas”. ¿Cómo construir esas comunidades epistémicas? Respondemos esta pregunta desde nuestro involucramiento en el trabajo con organizaciones rurales.

Primero, que líderes de organizaciones campesinas, indígenas y afrodescendientes, organicen su conocimiento de forma sistemática y permanente, y lo hagan en alianza con intelectuales del sur y del norte; construir una capacidad de largo plazo que expanda, corrija, genere y catalice saberes, dejando atrás la tradición oral y el ser solo movimientos reactivos ante el extractivismo y el monocultivismo. Las soluciones para hacer posible los Acuerdos de París vendrían de ese tipo de procesos que desarrollen capacidades en el largo plazo.

Segundo, esa capacidad propia debe combinarse con procesos de experimentación e innovación de rutas con diversas perspectivas y en la medida que sus organizaciones se consoliden basado fundamentalmente en recursos propios y en recursos generados por la captura de carbono. Las iniciativas de PSA deben ser leídas desde esa capacidad endógena, desde las prácticas de diversificación, la lógica de territorios donde las poblaciones cuidan las tierras, y desde las organizaciones de base que expandan sus capacidades de gestión de los bienes comunes. Se trata de que las familias y poblaciones puedan ver el cambio climático desde sus propias vidas, organizaciones y comunidades, mitigando el cambio climático, en lugar de verse como seres minúsculos ante el 'complejo' e 'incierto' cambio climático, como individuos aislados en entramados de mercados abstractos. 
Tercero, con esa capacidad de producir conocimiento e innovar modos de mitigación del cambio climático como un modo de vida diferente implicando cambios personales y renovación organizacional, las familias campesinas, indígenas y afrodescendientes necesitan reconquistar áreas de tierra profundizando su relación con la tierra, ampliando sus territorios como "lugar de aquellos que cuidan la tierra"21 bajo la premisa de que la equidad ecológica, social y económica son inseparables, y que por lo tanto la desigualdad de género, étnica y generacional son partes de la degradación ambiental. En este proceso, las políticas del estado y de los organismos para mitigar el cambio climático deben responder a la perspectiva mencionada con rotación de cultivos, diversificación, retroceso en el sistema de monocultivo y en el extractivismo, y equidad social y económica. De esta manera, esa coordinación de prácticas y políticas serían la base para que los Acuerdos de París se lleven a cabo y se profundicen para lograr una meta de calentamiento menor al $1.5^{\circ} \mathrm{C}$, fomentaría prácticas novedosas en lo ecológico, lo social y lo económico, reduciría la pobreza y la desigualdad, lo que es coherente con la meta de los Objetivos de Desarrollo Sostenible, de no dejar atrás a ni una persona pobre para el 2030.

Concluyendo, el poema citado al principio del texto es del pueblo indígena Sámi, ubicado en Noruega, Suiza, Finlandia y Rusia, un pueblo que lucha porque le reconozcan sus tierras. Ellos nos recuerdan que aún hablamos el lenguaje de la tierra, que la clave es volver a conectarnos con la tierra y aprender a relacionarnos con ella. J. Laiti, del pueblo Sámi, afirma que reconocer que nos pertenecemos uno al otro nos lleva a amar la vida, usar la naturaleza como fuente de vida, y a convencernos de que vivimos en $-\mathrm{y}$ estamos hechos por- la tierra ${ }^{22}$. Este cambio de relación con la naturaleza es posible si hay cambios personales y renovación organizacional, como nos lo recuerda el Papa Francisco en su Encíclica Laudato Sí: "no habrá una nueva relación con la naturaleza sin un nuevo ser humano." Y con estos dos pasos, dar el tercero, siguiendo al Proverbio Africano, "si quieres ir rápido, ve solo; si quieres llegar lejos, ve acompañado.” Ante el sistemático acoso de las corporaciones (mercado), la construcción de comunidades epistémicas con las familias campesinas y pueblos indigenas y afro-descendientes, grupos que han persistido siglos a ese acoso, ahora desarrollando sus capacidades de organizar y producir su conocimiento e innovaciones, un proceso acompañado en un marco de alianza global, y en constante cambio personal, puede realmente hacer diferencia en mitigar el cambio climático. Eso puede ser superar la "resaca". Eso es llegar lejos.

\section{Agradecimientos}

Este trabajo se ha beneficiado de los comentarios y sugerencias de P. Marchetti, F. Huybrechs, G. Delmelle, K. Kuhnekath, D. Kaimowitz, J. Bastiaensen y T. De Herdt. También de las reflexiones emanadas en un taller con líderes de organizaciones rurales (cooperativas y asociaciones) y de representantes de organismos del país y del exterior.

21 Esta frase de las mujeres de la comunidad afrodescendiente de La Toma del Cauca (Colombia), fue recogida por Escobar (2016).

22 Ver entrevista a Jenni Laiti en: http://uralistica.com/profiles/blogs/jenni-laiti-is-looking-out-for-smi-interests 


\section{Referencias bibliográficas}

Beck, U. (1986). La Sociedad del riesgo: Hacia una modernidad. Barcelona: Editorial Paidós.

Burke, M., Hsiang, M.S. \& Miguel, E. (2015). Global non-linear effect of temperature on economic production. Nature 527, Macmillan Publishers Limited.

Campos, V. (2016). El acuerdo climático de París es claramente insuficiente. Envio (406).

Chambers, R. (2014). Perverse Payment by Results: Frogs in a pot and straitjackets for obstacle courses. IDS, Sussex University. Recuperado el 6 de agosto de 2015, de https://participationpower.wordpress.com/2014/09/03/perversepayment-by-results-frogs-in-a-pot-and-straitjackets-for-obstacle-courses/

Correa, R. (2015). Por el hermano viento, por el aire, la nube, el cielo sereno y todo tiempo. Correos, 7 (42). Managua: Instituto de comunicación Social.

De Biase, L. (2014). What scientific idea is ready for retirement? en: Edge, https:// edge.org/response-detail/25425

Escobar, A. (2016). Desde abajo, por la izquierda y con la Tierra. Contrapuntos, Serie Desafíos Latinoamericanos (7).

Hansen, J., Sato, M., Hearty, P., Ruedy, R., Kelley, M., Masson-Delmotte, V., Russell, G., Tselioudis, G., Cao, J., Rignot, E., Velicogna, I., Kandiano, E., von Schuckmann, K., Kharecha, P., Legrande, A.N., Bauer, M., \& Lo, K. W. (2015). Ice melt, sea level rise and superstorms: Evidence from paleoclimate data, climate modeling, and modern observations that $2^{\circ} \mathrm{C}$ global warming is highly dangerous. Atmos. Chem. Phys. Discuss., 15.

Hardin, G. (1968). The tragedy of the commons. Science, 162 (3859), pp. 1243-1248. Jorgenson, A.K. (2006). Unequal Exchange and Environmental Degradation A Theoretical Proposition and Cross-National Study of Deforestation. Rural Sociology 71 (4).

King, D., Browne, J., Layard, R., O’Donnell, G., Rees, M., Stern, N. \& Turner, A. (2015). A Global Apollo Programme to Combat Climate Change. Recuperado el 05 de enero de 2016, de http://cep.lse.ac.uk/pubs/download/special/ Global_Apollo_Programme_Report.pdf

Marchetti, P. E. (2015). No Recipes for Planetary Crisis: Epistemic Communities and Climate/Energy Policy Architectures. Mimeo: Guatemala: Universidad Rafael Landivar.

Mendoza, R. (2004). Un espejo engañoso: imágenes de la frontera agrícola. Envío (265). Managua: IHCA-UCA. Recuperado el 05 de mayo de 2015, de http:// www.envio.org.ni/articulo.php?id=2069

Moore, J. W. (2015). Capitalism in the Web of life. Estados Unidos: VersoBook.

Nepstad, D., et al. (2014). Slowing Amazon deforestation through public policy and interventions in beef and soy supply chains. Science, 344 (6188).

Olson, M. (1965). The Logic of the Collective Action. Cambridge, MA: Harvard University Press.

Oquist, P. (2015). La posición de Nicaragua. Correos, 7 (42). Managua: Instituto de comunicación Social. 
Ortíz, I. \& Cummins, M. (2012). La distribución del ingreso en 141 países. Nueva York: UNICEF. Recuperado el 10 de mayo de 2015, de http://www.unicef. org/socialpolicy/files/Desigualdad_Global.pdf

Ostrom, E. (1990). Governing the Commons: The Evolution of Institutions for Collective Action. Cambridge: Cambridge University Press

Picketi, T. (2015). Carbon and inequality: from Kyoto to Paris. Paris School of Economics. Recuperado el 05 de enero de 2016 de http://piketty.pse.ens.fr/files/ ChancelPiketty2015.pdf

Reynolds, L. (2013). Agriculture and Livestock Remain Major Sources of Greenhouse Gas Emission. Worldwatch Institute. http://www.worldwatch.org/agricultureand-livestock-remain-major-sources-greenhouse-gas-emissions-0

Robinson, W. (2003). Transnational conflicts. Central America, Social change, and Globalization. London: Verso

Van Hecken, G., Bastiaensen, J. \& Huybrechs, F. (2015). What's in a name? Epistemic perspectives and Payments for Ecosystem Services policies in Nicaragua. Geoforum (63).

Verbruggen, A. (2015). Self-governance in global climate policy: An essay. Amberes: University of Antwerp. 